\title{
Integrated pest management for Jatropha Carcus plant: An Impulsive control approach
}

\author{
Jahangir Chowdhury ${ }^{1}$, Fahad Al Basir ${ }^{2}$, Xianbing $\mathrm{Cao}^{3}$, and Priti Roy ${ }^{4}$ \\ ${ }^{1} \mathrm{RCC}$ Institute of Information Technology \\ ${ }^{2}$ Asansol Girls' College \\ ${ }^{3}$ College of Science Beijing Technology and Business University \\ ${ }^{4}$ Jadavpur University
}

July 3, 2021

\begin{abstract}
In this research, an integrated pest management model using impulsive differential equations has been investigated for Jatropha curcas plantation to control its natural pests through relying on the release of infective pest individuals and spraying of chemical pesticides. Using Floquet's theory and the small amplitude perturbation method, it is obtained that there exists an asymptotically stable susceptible pest eradication periodic solution when the release amount of infected pest is larger than the critical maximum value (or strength of chemical pesticide spraying is larger than some critical maximum value). Also, we have established the permanence of the system. After comparison, it is explored that integrated pest management is more effective than biological control or chemical control. Finally, verify the analytical results through numerical simulation.
\end{abstract}

\section{Hosted file}

JC_PEST_CONTROL.pdf available at https://authorea.com/users/423472/articles/528863integrated-pest-management-for-jatropha-carcus-plant-an-impulsive-control-approach 